\title{
What is alcoholic fermentation? A study about the alcoholic fermentation conception through the history
}

\author{
Cardoso, C.A. F.; and Kurtenbach E.
}

Departamento de Bioquímica Médica, ICB/CCS/UFRJ.CEP. 21941-590, Rio de Janeiro, RJ, Brazil

This work shows the historical development of the alcoholic fermentation conception, based on experimental results obtained from European scientists, from Renascence to the beginning of $20^{\text {th }}$ century (1930). From this, five concepts were identified for the phenomenon: putrefactive, spiritual, chemical, biological and biochemical. The current conception of alcoholic fermentation was also evaluated. For this proposal, three groups of teachers were interviewed through the question? What is alcoholic fermentation? The $\mathrm{P}$ group (pilot, $\mathrm{n}=12$ ) made of professionals that teach on secondary and high schools, group A composed of PhD's from the Center of Technology Education - NUTES (n=9) and group B from Department of Medical Biochemistry (called group B, $n=41$ ) both of Federal University of Rio de Janeiro, respectively. Key words associated with the fermentative process were identified identify in the interviewees answers. The group A components mentioned only six key words and pointed out the alcoholic fermentation products. Differently, subjects from $\mathrm{P}$ and B groups cited a higher number and also more unusual key words $(\mathrm{n}=9$ and 12 , respectively). We also analyzed their answers throughout fermentative descriptive words (sugar, alcohol, carbon dioxide, anaerobic, yeast and ATP). These words were established after an evaluation of alcoholic fermentation concept stated in the Biology/Biochemistry books most adopted in high schools and Universities. Our analysis showed that group A used only three descriptive words (sugar, alcohol and yeast) while components of group B used all the selected descriptive words. However, only one interviewee used all the six words together. From this analysis, we proposed that the chemical concept of alcoholic fermentation prevailed on the other concepts found on the historical research (spiritual, putrefactive, biological e biochemical). Supported by: FAPERJ, FUJB, FESO. 